\title{
Endogenous Innovation Potential: Regional SMEs' Perspective in Emerging Economies
}

Submitted 19/07/20, $1^{\text {st }}$ revision $24 / 08 / 20,2^{\text {nd }}$ revision 19/09/20, accepted $30 / 09 / 20$

\author{
Jasińska-Biliczak Anna ${ }^{1}$
}

\begin{abstract}
:
Purpose: The objective of this paper is to determine the endogenous innovation potential of regional SMEs in emerging economies (EE). The presented research examines where the SME sector stands within the economy, especially an emerging one, with particular emphasis on the circumstances surrounding business innovation and an innovative economy in conditions of sustainable development.

Design/Methodology/Approach: A current understanding of the concept of SMEs along with the consequences for enterprises that arise from their inclusion within the analyzed sector is described. To achieve this goal, a group of innovatory indicators have been developed that are particularly important for the growth of the innovative potential of enterprises in the SME sector. Activities are also indicated that are particularly important for the development of the innovative potential of this sector. A research hypothesis concerning the endogenous innovatory activity of the SMEs in the region under analysis is proffered in this work.

Findings: On an empirical level, based on the analysis, it can be pointed out that the key to competitiveness is innovation, and the pace of change in techniques, technology and organization means that only an enterprise capable of introducing innovative changes can survive in the market.

Practical Implications: The enterprises surveyed, in terms of SME in the Opole Voivodeship, Poland, are characterized by innovatory potential. This will contribute to the perception of this sector not only as the dominant one in terms of quantity when considering all the enterprises on the market, but also as an equal partner among innovative enterprises of the region.

Originality/Value: Relevant to the development of the whole SME sector is the fact that it not only derives from external innovatory potential but is itself increasingly a source and driving force. Research fulfils the gap in the using new tool - neural networks (NN) to analysis of economical phenomenon such as innovational potential of enterprises, establishes the model concerning the use of a group of innovativeness indicators for the growth of enterprise innovativeness and purposes new definition of innovation as well.
\end{abstract}

Keywords: Regional development, innovation, SMEs, emerging economy, neural networks.

JEL codes: O18, O31, R11.

Paper type: Research article.

${ }^{1}$ Opole University of Technology, Faculty of Economics and Management, Department of Economics, Finance and Regional Research, a.jasinska-biliczak@po.edu.pl 


\section{Introduction}

When considering innovations on a theoretical level, it is necessary to describe the various possible features of this concept. It should be treated as a trend in the theory of economic and political science as well as entrepreneurship and as a direction for created and implemented policies (regional, global and economic development) (Fagerberg, 2006; Cantwell and Piscitello, 2000; Sachs 2015; Malik and Jasińska-Biliczak, 2020). Not without significance is the practical meaning of this concept, inextricably linked to real changes, trends and directions in business development and the underlying causes.

The need to process a large amount of statistical data describing research and innovation lies at the heart of the development of indices of innovation (Atkinson and Stiglitz, 1969). They reflect new ideas of innovation emerging in response to a change in economic and social practice. The development of indicators of innovation dates to 1970s and 1980s (Cantwell, 1989; Mansfield, 1975), when they helped describe the theories of innovation that arose at that time. Initially, two methods were used to measure innovation - material (measurement of the number and nature of innovations in actual existence) and personal (research on the enterprises that introduced the innovations) (Jick, 1983). The former is now rarely used because there are too many innovations being introduced for them all to be described and studied. In turn, the personal method relies on the research of enterprises. The questions used in this method relate to various aspects of the innovatory process in industry and services, the quantity of funds allocated for innovatory activities and the factors that strengthen or restrict innovation. They also concern the effects of innovation, sources of information for innovation, business operations and diffusion of innovation. This method is in line with the "Oslo methodology" recommended nowadays by Eurostat (Oslo Manual, 2005).

The purpose of this article was to determine the endogenous innovation potential of regional SMEs in emerging economy.

The research methodology is based on the neural analysis use. A current understanding of the concept of SMEs along with the consequences for enterprises that arise from their inclusion within the analyzed sector is described. In order to achieve this goal, a group of innovatory indicators have been developed - on the basis of a survey among 381 regional enterprises with following structure: microenterprises $-95,56 \%$ (366), small enterprises - 3,55\% (12), medium-sized enterprises $-0,89 \%$ (3), representative for the regional SMEs structure - that are particularly important for the growth of the innovative potential of enterprises in the SME sector.

The author purposes, as the novelty, fulfilling the gap in the using new tool (neural networks) to analysis of economical phenomenon such as innovational potential of enterprises, establishes the model concerning the use of a group of innovativeness 
indicators for the growth of enterprise innovativeness and purposes new definition of innovations as well.

\section{Emerging Economies: Towards Developed Economies}

An emerging market economy (EME) is defined as an economy with low to middle per capita income (Yeyati and Williams, 2012). EMEs are also considered to be fast-growing economies. Emerging economies (EE) promise huge potential for growth (Jasińska-Biliczak, 2019), but also pose significant political, monetary, and social risks. Economic growth enables EE to gradually close the gap with more developed economies. Activities that develop an economy in transition may include increasing standards of living (Jasińska-Biliczak and Malik 2020), developing a competitive industrial and commercial base, and improving infrastructure.

High standards of living in many countries have been equated with education, computer usage, and the ability to innovate. The key factor for effective change from an EE to a developed status economy is the country's strong and continuous economic growth (Jantunen, 2005; The Johannesburg Declaration, 2002). As an emerging market, a country embarks on an economic reform program that will lead to stronger and more responsible economic performance levels, as well as transparency and efficiency in the capital market. One key characteristic of an EME is an increase in both local (Jasińska-Biliczak, 2012) and foreign (Kowal et al., 2017) investment (portfolio and direct). Growth in investment in a country often indicates that the country has been able to build confidence in the local economy.

Furthermore, an EME must consider local political and social factors as it attempts to open its economy to the world. The people of an emerging market, accustomed to being protected from the outside world, can often be distrustful of foreign investment (Magee et al., 2013; Heakal, 2017). In accordance with the MSCI 2017 Emerging Markets Index (MSCI 2017 Emerging Markets Index; Shaker, 2015), emerging markets in the Americas are Brazil, Chile, Colombia, Mexico, and Peru; in Asia are China, India, Indonesia, Korea, Malaysia, Pakistan, Philippines, Taiwan, and Thailand; in Europe the Middle East and Africa Czech Republic, Egypt, Greece, Hungary, Poland, Qatar, Russia, South Africa, Turkey, and the United Arab Emirates. Therefore, it is reasonable to analyze Poland as one of the EE of Europe.

\section{Research Methodology}

The Opole Voivodeship in Poland was selected for the analysis of innovatory activities in the SME sector in EE. It is one of the five provinces (apart from Lower Silesia, Lubuskie, Wielkopolskie and Zachodniopomorskie) that comprise the macro-region of Western Poland, characterized by a high degree of competitiveness and favorable living standards and a high quality of life. The Opole Voivodeship belongs to a group of small European regions with a population of around one million inhabitants. Among the characteristics of the analyzed region, mention 
should be made of its strong connection with the German economy and the largest international migration of the population in the entire country. It is not without significance that the multiculturalism of such a small region, resulting from historical and cultural changes, determines its identity. It is also affected by depopulation caused by demographic trends, which is one disadvantage of the region. Action taken by the region's authorities has aimed at increasing the number of inhabitants of the region, which in turn may contribute to the fact that the proportion of its population in retirement age will be one of the highest in the country by 2030 .

To achieve the goals set, a thorough and critical review of literature regarding innovation in the SME sector was made. An original empirical study based on primary data was carried out. At the methodological level, a new method was implemented, involving the use of neural networks to study endogenous innovation in the analyzed sector.

A research hypothesis concerning the endogenous innovatory activity of the SME sector in the region under analysis is proffered in this work:

Hypothesis $(\boldsymbol{H})$ : the basis for innovativeness of enterprises in the SME sector is the use of existing links between endogenous activities in individual enterprises in this sector (including financial outlays for innovation).

Formulating the hypothesis, critical analysis of literature was considered, according to which research and development $(R \& D)$ is treated as a basic indicator for international comparisons of innovativeness. The Lisbon Strategy is related to this indicator, with its aim to increase the level of R\&D spending to 3\% of GDP in 2010 (Wim Kok Raport, 2004). It should be noted that the measurement of innovativeness is difficult due to the lack of clearly defined attributes of innovation. The proposed measurements describing this phenomenon assess selected aspects of it, sometimes to synthesize the measurements in the form of an innovation index. In view of the above, there is justification for analyzing the innovatory potential of this sector of enterprises on a regional basis.

\section{Results}

The starting point for the study was a declaration that qualitative and quantitative methods should be perceived as complementary, and not competitive. This leads to a fusion of qualitative and quantitative research. The subject scope of the study is consistent with the "Oslo methodology" and thus includes questions related to the basic issues falling within the scope of innovation.

Innovative changes identified in enterprises become markers of their internal development using their own resources and, above all, the development of the innovative potential of these enterprises. The initiative of business innovativeness is 
more and more often endogenous in nature. The analyzed sector increasingly shows a tendency to initiate conduct and activity aimed at seeking and implementing innovative solutions.

The study attempts to use NN to predict (regression, classification) revenues (Schmidhuber, 2015) from innovations in the small and medium enterprise sector. For graphical interpretation, ROC curves were used - a tool for assessing the classifier and providing a description of its sensitivity and specificity. An attempt was made to build a model on $\mathrm{NN}$ in the field of regression networks. The STATISTICA program was used, which has an inbuilt tool for creating NN. The obtained results, in the form of correlation coefficients for the aggregates - training $(70 \%)$, validation $(15 \%)$ and testing $(15 \%)$ - characteristic for the applied method, were optimistic due to the fact that for each aggregate they were above 0.8 for the best value from the network. The best network obtained in the study is the MLP 198-1 (multilayer perceptron) with 19 neurons, 8 layers of hidden neurons and one neuron at the output.

When creating the network, an approach was used whereby the program could choose from MLP (multilayer perceptron) and RBF (radial) networks. The activation functions available and taken into account when creating the network are as follows: linear, logistic, hyperbolic tangent (tanh), exponential and sine. All functions were applied to hidden neurons (8) and output neurons (1). Also the program was able to choose from MLP (multi-layer perceptron) and RBF (radial) networks. In the course of the NN analysis, the 30 best networks out of 2000 created by the program were selected. For the final check of the regression network, an attempt was made to make predictions for 10 "new" observations - i.e. ones unknown to the network. The distribution of the dependent variable and the output variable for the training set is illustrated in Figure 1.

Figure 1: Distribution of dependent variable (income from selling the innovative goods/services) and output variable for the training set.

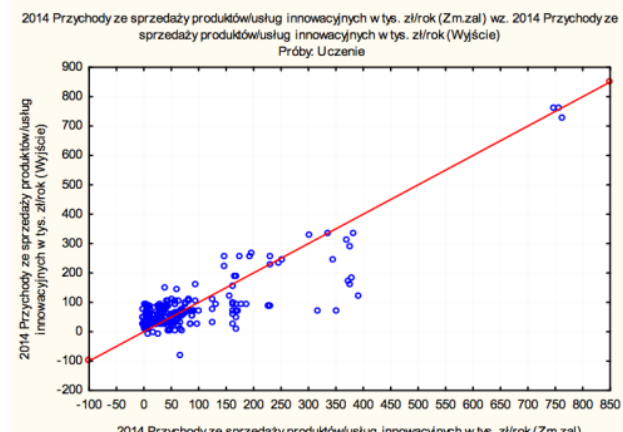

Source: Developed by the author.

It can be concluded that the NN is at its most average when predicting revenues from the sale of innovative products/services (the closer to the red line the better). 
The red line marked on the graph is a straight $\mathrm{Y}=\mathrm{X}$ line, so if the network were to perfectly predict actual values, then the blue points would be located perfectly on this line. The accuracy of the prediction of the NN selected for analysis (variable: income from selling the innovative goods/services) is shown in Figure 2.

Figure 2: Accuracy prediction of the selected network.

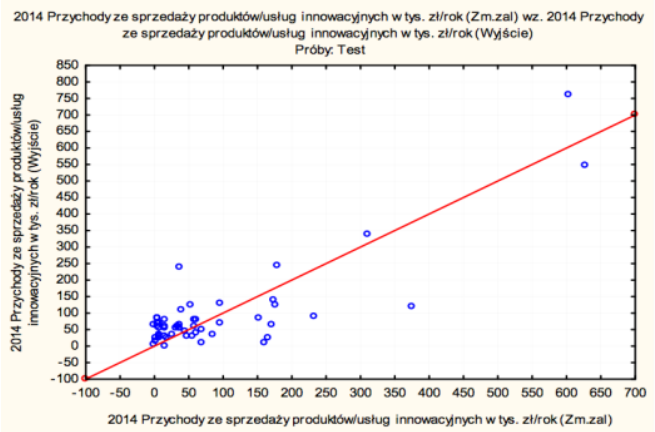

Source: Developed by the author.

Based on the research carried out using $\mathrm{NN}$, it can be concluded that $\mathrm{NN}$ for analyzing data are applicable when solving a classification problem. Table 1 presents the SOS mistake and function for active neuron values.

Table 1. The SOS mistake and function for active neuron values of hidden and initial neurons as well as coefficients of correlation for individual subsets.

\begin{tabular}{|l|l|}
\hline The rate & Value \\
\hline network Id & 10 \\
\hline network name & MLP \\
\hline quality - learning & 0,850802 \\
\hline quality - test & 0,835018 \\
\hline quality - validation & 0,877613 \\
\hline mistake - learning & 1789,263 \\
\hline mistake - test & 2759,572 \\
\hline mistake -validation & 1752,815 \\
\hline algorithm of & BFGS 33 \\
\hline mistake function & SOS \\
\hline activation - hidden & Exponential \\
\hline activation - outputs & Tanh \\
\hline
\end{tabular}

Source: Developed by the author.

In the case of the analysed network, there is no need to delete any variable, because each one in fact contributes some information that is relevant to the network. For the final check of the regression network, an attempt was undertaken to make forecasts 
for 10 "new" observations not yet seen by the network. The results of this analysis are presented in Table 2.

Table 2. The forecast values for ten networks

\begin{tabular}{|l|l|l|}
\hline Real values & Forecast values & Relative error \\
\hline 4 & 70,8647 & $1671,6 \%$ \\
\hline 17,5 & 29,7078 & $69,8 \%$ \\
\hline 9,4 & 27,0946 & $188,2 \%$ \\
\hline 6,3 & 26,4423 & $85,5 \%$ \\
\hline 92,7 & 60,0034 & $852,4 \%$ \\
\hline 165,5 & 68,8991 & $25,7 \%$ \\
\hline 326,2 & 164,5069 & $0,6 \%$ \\
\hline 546,3 & 128,9831 & $60,5 \%$ \\
\hline 67,4 & 184,3686 & $66,3 \%$ \\
\hline & 69,9078 & $3,7 \%$ \\
\hline
\end{tabular}

Source: Developed by the author.

During the analysis of data via the NN, a test was also carried out to check the normality of the Shapiro-Wilk distribution, which rejected H0, so the distribution of residues is not a normal distribution. An attempt was undertaken to make a classification network that will divide the observations into two subsets taking into account the same explanatory variables that were used in the construction of the regression network. To this purpose, a new variable was created that divided all observations into two sets:

1 - enterprises whose revenues from sales of innovative products/services are more than $20 \%$ of total revenues,

0 - enterprises whose revenues from sales of innovative products/services are less than $20 \%$ of total revenues.

After making such a division (coding of variables), a clear disproportion emerged in the number of individual sets. A decision was made to leave all available observations classified as " 1 " and to draw a very similar number of observations from the remaining observations classified as " 0 ". Ultimately, the sets included: " 1 " - 82 and "0" - 81 observations. A set created in this way enabled a balance to be maintained between the groups.

For the purposes of analysis, the same division into training (70\%), testing $(15 \%)$ and validating (15\%) sets was applied. To check the network in terms of classification, a set of 4 observations (two from one group and two from the other) was created, which is not visible to the network at any stage of their creation. The 
same approach was applied as for the regression network; both MLP and RBF (described earlier) can be created, and the same functions for hidden and output neurons were also chosen as for regression. In addition, the option of weight reduction was also selected, which enables a network to be obtained with lower weights, and thus protected to some extent against over-training and one which better generalises knowledge and works by modifying the error function to penalise the network for large weights. This results in a compromise between the quality and complexity of the network. Too much reduction can ruin network quality. The program was to select the 30 best networks out of 2000 created.

After analysing the obtained results and the classification matrix, it was decided that MLP 18-8-2 is the best network, i.e. a multilayer perceptron with 18 input neurons, 8 hidden neurons and two output neurons responsible for the two groups into which the observations are to be classified. The classification results obtained by the network for both the training and testing set are presented in the Tables $3 \mathrm{a}$ and $3 \mathrm{~b}$.

Table 3a. Values of results obtained by the network - training set

\begin{tabular}{|l|l|l|l|}
\hline MLP 18-8-2 & Dependent variable & Dependent variable & All \\
\hline Total & 57 & 58 & 115 \\
\hline Correct & 49 & 46 & 95 \\
\hline Incorrect & 8 & 12 & 20 \\
\hline Correct $(\%)$ & $85,9649 \%$ & $79,3103 \%$ & $82,609 \%$ \\
\hline Incorrect $(\%)$ & $14,0351 \%$ & $20,6897 \%$ & $17,391 \%$ \\
\hline
\end{tabular}

Source: Developed by the author.

Table 3b. Values of results obtained by the network - testing set

\begin{tabular}{|l|l|l|l|}
\hline MLP 18-8-2 & Dependent variable & - Dependent variable & All \\
\hline Total & 57 & 58 & 115 \\
\hline Correct & 49 & 46 & 95 \\
\hline Incorrect & 8 & 12 & 20 \\
\hline Correct (\%) & $85,9649 \%$ & $79,3103 \%$ & $82,609 \%$ \\
\hline Incorrect (\%) & $14,0351 \%$ & $20,6897 \%$ & $17,391 \%$ \\
\hline
\end{tabular}

Source: Developed by the author.

It can be seen that the level of correct classifications, both for the training and the testing sets, falls at a very similar level. In both sets, the network copes better with classifying correctly into the " 0 " group, where the values exceed $85 \%$, while in the " 1 " group the values of correctly classified observations are slightly lower and range from $75 \%-80 \%$. Based on such data, the level of correctly classified observations was considered to lie at a satisfactory level, and therefore it was decided to test the network on new data. The results of the next test are shown in the following Table 4. 
Table $3 \boldsymbol{b}$. Values of results obtained by the network - testing set

\begin{tabular}{|l|l|l|l|}
\hline MLP 18-8-2 & Dependent variable & Dependent variable & All \\
\hline Total & 2 & 2 & 4 \\
\hline Correct & 2 & 2 & 4 \\
\hline Incorrect & 0 & 0 & 0 \\
\hline Correct (\%) & $100,0000 \%$ & $100,0000 \%$ & $100,000 \%$ \\
\hline Incorrect (\%) & $0,0000 \%$ & $0,0000 \%$ & $0,000 \%$ \\
\hline
\end{tabular}

Source: Developed by the author.

It can be seen that the network did not make any error in the classification of four previously unknown observations. Therefore, it can be concluded that the use of neural networks as a methodological tool for classification is definitely more justified than in the case of regression.

\section{Findings}

Considering that they were created for the purposes of a study based on real data, the results should be considered satisfactory and allow the use of networks to classify enterprises belonging to the SME sector in terms of a dependent variable (binary). Considering the indicators of innovations implemented in individual enterprises, it should be stated that in the Opole Voivodeship, all types of implemented innovations are important for the SMEs.

Thus, they also have an impact on the innovativeness of the analyzed sector through the occurrence of the phenomenon of knowledge transfer in enterprises, which in turn has an impact on the innovativeness of these enterprises. Such mutual interactions are important not only from the point of view of the benefits to the enterprises, such as the flow of knowledge between business entities or the latest experience of these entities and the realities of their operation. They relate in particular to knowledge transfer and making it accessible to other entities, whereby the transfer of knowledge includes two types of activities: transmission and absorption, where transmission means sending or presenting knowledge to a potential recipient, and absorption means the acceptance of knowledge for its use (either present or future). Such relationships also have an impact on the innovativeness of the entities in which they are introduced and contribute to regional development and its innovativeness.

It is also reasonable to state that the average number of people employed in the company and its actions in the field of corporate social responsibility simply translate into an increase in the innovativeness of the Opole Voivodeship SMEs.

Another variable - the ratio of revenue gained from innovation to expenditure on innovation - indicates their real impact on increasing the innovativeness of the SMEs in the Opole Voivodeship. Therefore, the results of the study enabled a positive verification of the hypothesis $(\mathrm{H})$. 
Based on the research, the special group of innovativeness indicators were identified for the SME sector, bringing the greatest impact upon its innovative development. They include product innovations that contribute to the creation of new jobs (as opposed to process innovations which, as a consequence of their implementation, result in a decrease in employment) and marketing innovations, due to the growing importance of the client and the role of intermediaries in the marketing operations of various enterprises. Transfer of knowledge is important to ensure interaction with the understood company environment. It stimulates the release of further endogenous innovation impulses, created in small and medium enterprises because of information or actions undertaken by external entities. The same applies to the indicator involving the company's own ongoing research and development (R\&D). A significant indicator of endogenous innovativeness within the SME sector is also the number of Corporate Social Responsibility activities undertaken by the company, which, as demonstrated by the study, has contributed to the generation of new jobs and remained closely connected with marketing innovations, thereby strengthening their effect.

The analysis helped to create a model for the conditions surrounding the growth of innovation in the small and medium-sized enterprise sector along with recommendations mainly for the management (owners and managerial staff) of this sector. The model concerns the use of a group of innovativeness indicators distinguished in the study for the implementation and growth of enterprise innovativeness, and it is illustrated in Figure 3.

Figure 3. Model of conditions for the growth of innovativeness in regional SME sector.

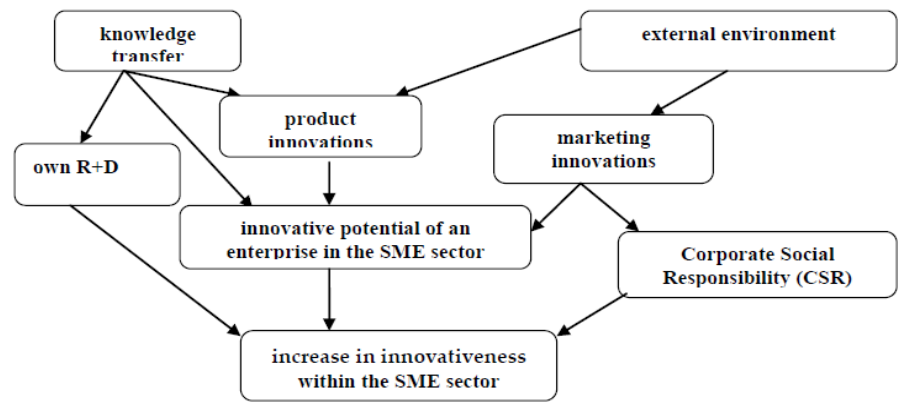

Source: Developed by the author.

When analyzing the model, it can be stated that the effective use of knowledge regarding the creation of conditions for the implementation of selected innovation indicators should result in the increase of innovativeness of individual enterprises in the SMEs. The indicators of endogenous innovative development of the SME sector identified in this way and the presented model constitute a coherent whole with present theories of regional development based on innovativeness and concentration of economic activities, thereby complementing them. 


\section{Discussion}

The basis for considerations on innovation or innovativeness within enterprises is the Schumpeter concept, which points to invention as the basis for innovation (Schumpeter, 1954), after which, during the very process of introducing innovation, three stages are distinguished. The first is the invention that constitutes the basis for the innovation. The second is the innovation itself, and the third - its prevalence, or imitation. Like innovations, innovativeness has no uniform, precise or widely accepted definition (Jasińska-Biliczak and Sitkowska, 2014). Considering fact that the source of innovation is the observation of market processes, and the implementation of innovation (Kowal et al., 2016) allows the company to gain a competitive advantage in the market, innovation and innovativeness are perceived as related to technological achievements occurring at earlier stages of an enterprise's development.

The emergence of new solutions is considered a gradual process of continuous adaptation (Thalassinos, 2007) and improvement of production methods and cycles, while the differences in innovativeness between industries, sectors of the economy (Malik and Jasińska-Biliczak, 2018) and finally the enterprises themselves reflect the unevenness of technological absorption in earlier periods (Ratanawaraha and Polenske, 2007; Younis and Nor'Aini, 2010). The effect of further development of research on innovations was the concept of technology accumulation, in which systemic and institutional factors are the most important.

Accordingly, the innovative application of a new solution in a new environment leads to the adaptation of innovations and depending on the state of the local technical and scientific potential (ERAC Report, 2012), this can then become the foundation for further innovations. Such a definition of the problem draws attention to the dynamic nature of innovation and combines advantages of technology and location, especially in relation to the local research and development potential. Innovations are also, according to numerous attempts in the literature to define such a concept definitively, new and better in relation to the original solutions, affecting the socio-economic conditions of life (Rese and Beier, 2011; Brunswicker and Vanhaverbeke, 2015; Johnson, 2015; Jasińska-Biliczak, 2019).

Innovations can also be coming up with new ideas and implementing them to come up with new products or processes. Research shows that the differential factor regarding innovation is not only the size of the enterprise, but also areas such as creativity, the ability to use the innovatory potential in practice or to predict future events and trends, contact with customers and recognizing their needs, IT resources or operational flexibility.

In both, theory and business practice, an évolution has been observed in terms of the définition of innovation. A new paradigm associated with open innovations requires companies to use both external and internal ideas as well as commercialization 
channels. Thus, it breaks traditional views on the self-sufficiency of organizations in the field of innovation, enabling the mutual flow of intellectual property, various ideas and their creators between the company and its surroundings. In recent years, the concepts of innovation and innovativeness have become symbols of a modern society. Innovation starts to be identified with the creation of new objects, which is associated with the danger that the widespread use of this word may reduce the creativity of those involved in it.

For the purposes of analysis, the author has formulated own definition of innovation, in which innovations are defined as a multidimensional instrument constituting a compilation of the various endogenous activities performed by an economic entity and the external stimulants affecting it, stimulating the activity of this entity in order to gain a competitive advantage and define its own path of development.

On an empirical level, based on the analysis, it can be pointed out that the key to competitiveness is innovation, and the pace of change in techniques, technology and organization means that only an enterprise capable of introducing innovative changes can survive on the market.

\section{Conclusions}

Relevant to the development of the SME sector is the fact that it not only derives from external innovatory potential but is itself increasingly a source and driving force. The enterprises surveyed, in terms of SME in the Opole Voivodeship, are characterized by innovatory potential. This will contribute to the perception of this sector not only as the dominant one in terms of quantity when considering all the enterprises on the market, but also as an equal partner among innovative enterprises of the region.

The nature of innovation is complex because it covers issues in the field of science, technology, and the economy. The complicated circumstances surrounding it means that despite rich and expanding literature, it remains unrecognized. The research fills in the gap related to the endogenous circumstances of innovativeness of SME on a regional basis. It is, in the context of the development of economic sciences, a novel approach to the problem of examining and determining new endogenous stimulants in the SME sector.

The applicational contribution of the research may provide an indication of implementation problems, for which the test results may be applicable, verification and confirmation of theoretical considerations concerning the specificity of conditions for innovation in the SME sector in the region as well as drawing conclusions and recommendations on its current and future development. The featured application may be perceived as theoretical, while methodological contributions of the research include the development of a group of innovative indicators that are particularly important for the growth of the innovative potential of 
the SME sector, analysis using neural networks as a modern research method, obtaining reliable, original research results as well as mapping out an original vision of the future of innovatory development of the SME sector. The research may also be applied to determine areas where the theory of innovation may be used in relation to the SME sector, the verification and confirmation of theoretical considerations concerning the specificity of conditions for innovation in its sector in the region as well as drawing conclusions and recommendations on the current and future development of innovation in the SME sector.

\section{References:}

Atkinson, A.B., Stiglitz, J.E. 1969. A new view of technological change. The Economic Journal, 79(315), 573-78.

Brunswicker, S., Vanhaverbeke, W. 2015. Open Innovation in Small and Medium-Sized Enterprises (SMEs): External Knowledge Sourcing Strategies and Internal Organizational Facilitators. Journal of Small Business Management, 53(4), 12411263, http://dx.doi.org/10.2139/ssrn.2351047.

Cantwell, J.A. 1989. Technological Innovation and Multinational Corporations. Basil Blackwell, Oxford.

Cantwell, J., Piscitello, L. 2000. Accumulating technological competence: its changing impact on corporate diversification and internationalization. Industrial and Corporate Change, 9 (1), 29-31.

European Union. 2004. Facing The Challenge. The Lisbon strategy for growth and employment. Report from the High Level Group chaired by Wim Kok, Office for Official Publications of the European Communities, ISBN 92-894-7054-2.

Fagerberg, J. 2006. Innovation: A Guide to the Literature. In Fagerberg, J., Mowrey, D.C., Nelson, R.R. (eds.), The Oxford Handbook of Innovation, The Oxford University Press, Oxford, 112.

Heakal, R. 2017. What is emerging market economy? At: https://www.investopedia.com/ articles/03/073003.asp 30.11.2017.

Jantunen, A. 2005. Knowledge-processing capabilities and innovative performance: an empirical study. European Journal of Innovation Management, 8(3), 336-349, https://doi.org/10.1108/14601060510610199.

Jasińska-Biliczak, A. 2012. Sektor małych i średnich przedsiębiorstw województwa opolskiego na tle polityki regionalnej Unii Europejskiej. Nierówności społeczne a wzrost gospodarczy, 28, 326-336.

Jasińska-Biliczak, A. 2019. The third sector-the new path towards the entrepreneurship of the future?-Polish insights. Ad Alta: Journal of Interdisciplinary Research, 9(2), 93-96, www.doi.org/10.33543/0902.

Jasińska-Biliczak, A., Malik, K. 2020. Measuring the Integrated Effectiveness of Regional Development: Directions for Regional Government. European Research Studies, 23(1), 389-403.

Jasińska-Biliczak, A., Sitkowska, R. 2014. Influence of small and medium enterprises sector at the change of innovation potential of Polish regions. Grant Journal, 3(1), 57-66.

Jick, T. 1983. Mixing qualitative and quantitative methods, triangulation in action. Maanem J. (ed.), Qualitative Methodology, London Sage, 51. 
Johnson, M.P. 2015. Sustainability Management and Small and Medium-Sized Enterprises: Managers' Awareness and Implementation of Innovative Tools. Corporate Social Responsibility and Environmental Management, 22(5), 271-285, https://doi.org/0.1002/csr.1343.

Kowal, J., Mäkiö, J., Jasińska-Biliczak, A. 2016. Business competencies as an innovation capability of IT users in Poland and Germany. Experimental study. ICTM 2016, 30.

Kowal, J., Makio, J., Jasińska-Biliczak, A. 2017. Business competencies and innovation capability in cross-border small regional enterprises. 2017 IEEE 15th International Conference on Industrial Informatics (INDIN). doi:10.1109/indin.2017.8104892.

Malik, K., Jasińska-Biliczak, A. 2018. Innovations and Other Processes as Identifiers of Contemporary Trends in the Sustainable Development of SMEs: The Case of Emerging Regional Economies. Sustainability, 10(5), 1361, https://doi.org/10.3390/su10051361.

Magee, L., Scerri, A., James, P., Thom, J.A., Padgham, L., Hickmott, S., Deng, H., Cahill, F. 2013. Reframing social sustainability reporting: Towards an engaged approach. Environment, Development and Sustainability. University of Melbourne, Australia, 15(1), 225-243, doi:10.1007/s10668-012-9384-2.

Mansfield, E. 1975. Organizational and Strategic Factors Associated with Probabilities of Success in Industrial R\&D. Journal of Business, 48 (2), 179-198.

MSCI. 2017. Emerging Markets Index, https://www.msci.com/market-classification.

Oslo Manual. 2005. Guidelines for Collecting and Interpreting Innovation Data, 3rd Edition, 163. ISBN: 978-92-64-01308-3.

Ratanawaraha, A., Polenske, K.R. 2007. Measuring the geography of innovation. The Economic Geography of Innovation, K.R. Polenske (ed.), University Press, Cambridge, ISBN-10: 0521689538, 214-231.

Report on the 2012 ERAC Mutual Learning Seminar on Research and Innovation Policies, Brussels. NESTI 2012.

Rese, A., Beier, D. 2011. Success factors for innovation management in networks of small and medium enterprises. R\&D Management, 42(2), Special Issue: Outsourcing R\&D (Part 2) Guest Editors: Hsuan, J., Mahnke, V. Papers by Bianchi et al., Ambos and Ambos, and Rese and Baier complete the special issue on outsourcing started in 41(1), 138-155, https://doi.org/10.1111/j.1467-9310.2010.00620.x.

Sachs, J.D. 2015. The Age of Sustainable Development. New York, Columbia University Press, 162-312, ISBN 9780231173155.

Schmidhuber, J. 2015. Deep learning in neural networks: An overview. Neural Networks, 61, 85-117, https://doi.org/10.1016/j.neunet.2014.09.003.

Schumpeter, J.A. 1954. Economic doctrine and method: an historical sketch. New York: Oxford University Press, OCLC 504289265. Translated from the 1912 original German, Epochen der dogmen - und Methodengeschichte.

Shaker, R.R. 2015. The spatial distribution of development in Europe and its underlying sustainability correlations. Applied Geography, 63, 304-314, doi.org/10.1016/j.apgeog. 2015.07.009.

Thalassinos, I.E. 2007. Trade Regionalization, Exchange Rate Policies and EU-US Economic Cooperation. European Research Studies Journal, 10(1-2), 111-118, DOI: 10.35808/ersj/167.

The Johannesburg Declaration on Sustainable Development. United Nations. World Summit on Sustainable Development, Johannesburg, South Africa, 26 August - 4 
September, 2002; Document A/CONF.199/L.6.Rev. - doi: ods-ddsny.un.org/doc/UNDOC/LTD/NO2/578/83/PDF/NO257883.pdf?OpenElement.

Yeyati, E.L., Williams, T. 2012. Emerging economies in the 2000s: Real decoupling and financial recoupling, Journal of International Money and Finance, 31(8), Elsevier, doi:citeseerx.ist.psu.edu/viewdoc/download?doi=10.1.1.607.1868\&rep=rep1\&type $=$ pdf.

Younis A.I., Nor'Aini, Y. 2010. Innovation Creation and Innovation Adoption: A Proposed Matrix Towards a better Understanding. International Journal of Organizational Innovation, 3(1-3). 